\title{
Long-term patency of coronary grafts with endoscopically harvested saphenous veins determined by contrast- enhanced electron beam computed tomography
}

Zev Davis, MD ${ }^{\mathrm{a}}$

Dave Garber, $\mathrm{PA}^{\mathrm{a}}$

Stanley Clark, MD ${ }^{\mathrm{b}}$

Howard Roth, MD

Vincent Bufalino, $M D^{b}$

Matthew J. Budoff, MD ${ }^{\mathrm{c}}$

Songshou Mao, MD ${ }^{\mathrm{c}}$

H. Kurt Jacobs, $\mathrm{PhD}^{\mathrm{d}}$

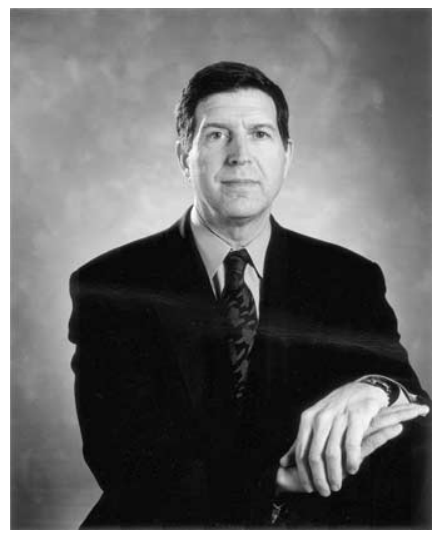

Dr Davis

From the Cardiac Surgery Associates ${ }^{\mathrm{a}}$ and Midwest Heart Specialists, ${ }^{\mathrm{b}}$ Edward Cardiovascular Institute, Edward Hospital, Naperville, Ill, Harbor-UCLA Medical Center and St Johns Cardiovascular Research Institute, ${ }^{\mathrm{c}}$ Torrance, Calif, and Central DuPage Hospital, Institute of Health and Care Management, ${ }^{\mathrm{d}}$ Winfield, Ill.

This study was funded by a grant from CardioVations, a Division of Ethicon, Inc, a Johnson \& Johnson Company, Somerville, NJ. Nycomed Amersham Imaging provided the Iohexol contrast dye for electron beam computed tomography.

Received for publication July 25, 2003; accepted for publication Oct 7, 2003.

Address for reprints: Zev Davis, MD, Cardiac Surgery Associates, Edward Hospital, 120 Spalding Drive, Suite 201, Naperville, IL 60504 (E-mail: zdavis@openheart.net).

J Thorac Cardiovasc Surg 2004;127:823-8

$0022-5223 / \$ 30.00$

Copyright () 2004 by The American Association for Thoracic Surgery

doi:10.1016/j.jtcvs.2003.10.051
Objectives: We determined the long-term patency rates of coronary artery grafts with endoscopically harvested saphenous veins.

Methods: Patency rates were established in 51 patients with 130 distal saphenous vein grafts using contrast-enhanced electron beam computed tomography at $3.74 \pm$ 0.65 years after coronary artery bypass grafting. A similar group of 50 patients with 131 distal grafts were studied prospectively using the same methodology at $0.7 \pm$ 0.19 years after coronary artery bypass grafting.

Results: The overall patency rates were $95.4 \%$ in the retrospective group and $95.3 \%$ in the prospective group. Sequential grafts tended to have a patency advantage over independent grafts.

Conclusions: These data compare favorably with reported patency rates for traditionally harvested saphenous veins. Endoscopic saphenous vein harvesting, in addition to previous favorable reports on pain, complications, and costs, is now shown to provide comparable or better patency rates in comparison with traditionally harvested veins.

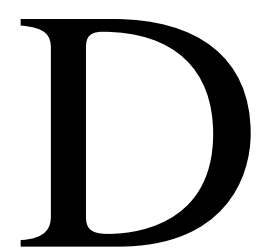

espite the advent, success, ${ }^{1-6}$ and increasing acceptance of endoscopic vein harvesting $(\mathrm{EVH})$ for coronary artery bypass grafting $(\mathrm{CABG})$, a single major concern is unresolved. The relative longevity of the endoscopically harvested saphenous vein remains unknown.

$\mathrm{We}^{6}$ and others ${ }^{1-5}$ have shown that EVH for the short term is safe and effective, with less leg pain and morbidity than traditionally harvested saphenous veins. Although there is concern that the vein may be subject to more intense manipulation during endoscopic harvest, which may lead to restenosis or occlusion, early histologic and physiologic studies ${ }^{2,5,7-9}$ do not support this. Further, indirect clinical studies ${ }^{10}$ show there is no increase in adverse events (death, myocardial infarction, or angina) at the 18-month follow-up.

We followed an early cadre of patients ${ }^{6}$ undergoing EVH for CABG to determine long-term graft patency by contrast-enhanced electron beam computed tomography (EBCT). In addition, we followed a matched group of more recent patients prospectively to examine the occurrence of early graft stenosis or occlusion. Because coronary angiography carries a procedural risk (especially in asymptomatic patients) 
and is expensive, we used contrast-enhanced EBCT, a reliable method to directly measure graft patency.

\section{Methods}

Patients who had undergone or were scheduled for CABG with endoscopically harvested saphenous veins were recruited for study. Patients undergoing a reoperation ( $\geq 2$ CABGs) were excluded. Cardiopulmonary bypass with cold cardioplegic solution was used in all cases. All anastomoses were constructed with distracted running sutures. This study was reviewed and approved by the institutional review board of Edward Hospital. All patients consented to join the study. Two groups of patients were studied. Group 1 was a retrospective group of 51 patients. These patients were a subset of those patients who comprised a study detailing the methods and outcomes of EVH. ${ }^{6}$ EVH was accomplished in the retrospective group with a single 2 - to $3-\mathrm{cm}$ incision medially above the knee. The greater saphenous vein was identified, and a space was created for the insertion of a subcutaneous dissector. A 300-mm $30^{\circ}$ endoscope was used for visualization, and a dissector was used for blunt dissection (CardioVations, Ethicon, Somerville, NJ). Endoscopic miniscissors were used for sharp dissection. Clips were used for large side branches and to close the most distal portion of the vein. Endoscopic sutures were used at the proximal portion of the dissection before vein removal.

Group 2 was a demographically similar set of 50 patients recruited prospectively. A similar technique was used, with addition of the use of an intraoperative Medi-Stim Butterfly (Medtronic, Minneapolis, Minn) device for flow and pulsatility index measurements.

Patients in Group 1 (retrospective) were selected for study by sequentially telephoning (maximum of 3 calls) each patient who met selection criteria until the requisite number of 50 was reached. A total of 133 patients were contacted. Patients in Group 2 (prospective) were asked to enroll in the study in a consecutive manner when they underwent their initial surgical consult for CABG. A total of 86 patients were asked to participate to reach the number of 50 participants.

The majority $(82 \%, \mathrm{n}=214)$ of grafts examined in this study were sequential grafts. There were $47(18 \%)$ individual grafts. Although most of these patients had an arterial graft placed at surgery, only saphenous vein grafts (SVGs) were examined in this study.

\section{EBCT Scans}

To determine patency, the relatively new technology of contrastenhanced EBCT scans was used. An Insight workstation (Neo Imagery Technologies, City of Industry, Calif) was used for reading the scans.

All scans were performed on an Imatron C150 Electron Beam CT scanner (General Electric-Imatron, South San Francisco, Calif). An antecubital intravenous catheter was inserted, and 18G to $20 \mathrm{G}$ hypodermic needles were used. All patients had electrocardiogram monitoring throughout the procedure. Image acquisition was gated to $60 \%$ of the respiratory rate interval. After scout imaging was obtained to determine the area of interest for scanning, circulatory time was determined using a timing run. Iohexol (20 mL) was injected over a period of 5 to 7 seconds, and scanning at timed intervals was performed over the ascending aorta. Image acquisition was initiated at the time required to reach $80 \%$ of the maximum contrast density in Hounsfield units within the ascending aorta. Images were obtained in $3 \times 2$-mm slice thicknesses from the base of the heart superiorly through the ascending aorta.

Patients with heart rates less than $60 / \mathrm{min}$ were treated with atropine to achieve rates greater than $60 / \mathrm{min}$ to avoid prolonged breath holding during scanning. All patients were given supplemental oxygen and instructed in breath-holding techniques. Immediately before image acquisition, all patients received a $0.4 \mathrm{mg}$ dose of sublingual nitroglycerin spray to maximize coronary vasodilatation.

Iohexol doses of 3 to $5 \mathrm{~mL} / \mathrm{s}$ were then administered for contrast opacification of the venous conduits. Combined with the timing run, $150 \mathrm{~mL}$ of contrast dye was used for the typical study. Images were then transferred to a Neo Imager Technology Insight workstation for data storage and analysis. Two-dimensional axial imagery, 3-dimensional reconstruction with volume rendering, maximum intensity projection, and 3-dimensional reconstructions were all used to interpret the images. Both Groups 1 (retrospective) and 2 (prospective) were interpreted independently by 2 experienced CT angiography readers (S.C. and M.B.) who were unaware of the other's readings.

Graft patency was categorically scored as (1) patent without evidence of disease; (2) patent, but with evidence of atherosclerotic disease defined as more than $50 \%$ occlusion; and (3) totally (100\%) occluded.

\section{Statistics}

This study was designed to provide an accurate description of the occlusion rate of the SVGs with time. Previous work $^{6}$ with the retrospective patient group had shown a clinically apparent occlusion rate of $2.6 \%$ at 1 year. With this rate and an estimated standard error of the population of $13.65 \%$, a sample size of 50 would give $95 \%$ confidence intervals such that we could accurately predict the true occlusion rate between $0 \%$ and $9 \%$ using 1-tailed tests. The Clopper-Pearson statistic ${ }^{11}$ was chosen to determine the confidence intervals. These data could then be compared among the 2 groups and historic controls.

Both univariate and multivariate logistic regression were used to determine the relative contribution of several variables to the outcome of total occlusion. In these analyses, if there were 1 or more total occlusions for any given patient, the dependent variable "occlusion" was listed as positive. Open but diseased vessels were tabulated as open for these analyses.

Data are presented as means \pm SDs for quantitative measures. Numbers and percentages are used for qualitative measures. Chisquare tests were used for incidence rate testing, and statistical analysis was aided by Systat 7.0 (SPSS, Chicago, Ill). Analysis of variance with Bonferroni tests was used for quantitative variables when contrasting the 2 subject groups to the previous patient population. Simple $t$ tests were used for contrasting only the 2 subject groups.

\section{Results \\ Demographics}

Groups 1 and 2 were similar in demographics (Table 1). Group 1 also closely reflected the demographics from the original group of patients from whom it was derived except 
TABLE 1. Demographic variables

\begin{tabular}{|c|c|c|c|c|}
\hline & Group 1 & Group 2 & $\begin{array}{l}\text { Comparative data } \\
\text { (Reference 6) }\end{array}$ & $P$ value \\
\hline Age (y) & $65.9 \pm 9.7$ (range $45.8-82.5)$ & $63.2 \pm 9.3(46.7-82.7)$ & $61.8 \pm 10.2$ (in 1997) & $P>.2$ \\
\hline Gender & $90.2 \%$ males & $74 \%$ males & $79.1 \%$ males & $P=.103$ \\
\hline Height (in) & $69.7 \pm 4.5$ & $68.1 \pm 4.5$ & $68.9 \pm 4.0$ & $P>.2$ \\
\hline Weight (lb) & $192.1 \pm 34.1$ & $193.3 \pm 41.1$ & $189.4 \pm 38.5$ & $P>.2$ \\
\hline $\begin{array}{l}\text { Number of distal saphenous } \\
\text { vein grafts }\end{array}$ & $2.5 \pm 0.8$ & $2.6 \pm 0.7$ & $2.5 \pm 1.0$ & $P>.2$ \\
\hline Current nonsmokers & $88.2 \% *$ & $92 \% \dagger$ & $52.7 \% * \dagger$ & $P<.001$ \\
\hline Diabetes (\% with) & $31.4 \%$ & $36 \%$ & $23.6 \%$ & $P>.20$ \\
\hline Hypertension (\% with) & $62.8 \%$ & $66 \%$ & $62.7 \%$ & $P>.20$ \\
\hline
\end{tabular}

* Indicates a difference between marked values at the indicated $P$ value.

for the proportion of current smokers, which was significantly greater at the original presentation. Although there seemed to be a higher percentage of male patients in Group 1 versus either of the other groups, this did not prove statistically significant overall $(P=.103)$ or compared with Group 2 alone $(P=.062)$.

\section{Overall Graft Patency Readings}

All grafts were categorically evaluated as open, diseased, or totally occluded by each of the 2 readers, independently. The operative reports indicated that 261 vein grafts were placed overall (Groups 1 and 2, sequential plus individual grafts). Both readers read all 261 grafts. The agreement between the 2 readers was $91.6 \%$ (239/261 grafts). Consensus readings were used for 19 of the remaining 22 grafts. Three grafts remained with different readings by the 2 readers.

\section{Patency Rates by Group}

In Group 1 (retrospective), the EBCT scan was performed in patients $3.74 \pm 0.65$ years (range 3.37-4.31 years) after the initial CABG. Of the 131 grafts in this group, 122 were open, 2 were diseased, 6 were occluded, and 1 was read either as open (S.C.) or diseased (M.B.). This latter graft is excluded from the following calculations. The open graft rate was $95.4 \%$ (124 open grafts; the diseased grafts were included in the open tally for analysis). The occluded graft rate was $4.6 \%$ (Clopper-Pearson 95\% confidence interval $1.97 \%-8.90 \%$ ). These data and the breakdown by sequential and independent grafts can be found in Table 2 .

In Group 2 (prospective), the EBCT scan was performed in patients $0.70 \pm 0.19$ years (range $0.47-1.11$ years) after the initial CABG. Of the 130 grafts in this group, 120 were open, 2 were diseased, 6 were occluded, and 2 were read as occluded/diseased and open/occluded by the 2 readers. These latter 2 grafts are excluded from the following calculations. Again placing the diseased grafts into the open tally, there was a $95.3 \%$ patency rate (122 open grafts) and $4.7 \%$ occlusion rate (Clopper-Pearson 95\% confidence in-
TABLE 2. Group 1 (retrospective) saphenous vein graft status

\begin{tabular}{lcccc}
\hline & $\begin{array}{c}\text { Number of } \\
\text { grafts }\end{array}$ & Open & Open but diseased & Occluded \\
\hline $\begin{array}{c}\text { Sequential } \\
\text { grafts }\end{array}$ & $112^{*}$ & 107 & 1 & 4 \\
$\begin{array}{c}\text { Independent } \\
\text { grafts }\end{array}$ & 18 & 15 & 1 & 2 \\
Total grafts & 130 & 122 & 2 & 6 \\
\hline
\end{tabular}

*One sequential graft was not resolvable by consensus; S.C. read it as open, and M.B. read it as diseased.

terval $2.00 \%-8.84 \%$ ). These data and the breakdown by sequential and independent grafts are shown in Table 3.

\section{Patency Rates by Type of Graft}

Although this study was not designed and powered to test the difference between sequential versus independent grafts, there seemed to be a higher overall rate of occlusion for the independent grafts versus the sequential grafts. The patency rates of sequential grafts versus independent grafts in Group 1 (retrospective) are given in Table 2. Without the input from the diseased grafts, the totally occluded rate was $3.57 \%$ (4/112) for the sequential grafts in Group 1. The respective rate for the independent grafts was $11.1 \%(2 / 18)$. This difference was not significant $(P=.466)$. The same analysis for Group 2 (prospective) (Table 3) showed occlusion rates of $2 \%(2 / 100)$ for the sequential grafts and $14.3 \%$ $(4 / 28)$ for the independent grafts. This difference was statistically significant $(P=.043)$. Combining the groups showed occlusion rates of $2.8 \%$ for the sequential grafts and $13 \%$ for the independent grafts, a significant difference $(P$ $=.017)$.

\section{Influence of Predictive Variables on Patency}

Factors including hypertension, number of distal grafts, total cholesterol, high-density lipoprotein, low-density lipoprotein, triglycerides, diabetes, smoking status, need for 
TABLE 3. Group 2 (prospective) saphenous vein graft status

\begin{tabular}{lcccc}
\hline & $\begin{array}{c}\text { Number of } \\
\text { grafts }\end{array}$ & Open & Open but diseased & 0ccluded \\
\hline $\begin{array}{c}\text { Sequential } \\
\text { grafts }\end{array}$ & $100^{*}$ & 97 & 1 & 2 \\
$\begin{array}{c}\text { Independent } \\
\text { grafts }\end{array}$ & $28 \dagger$ & 23 & 1 & 4 \\
Total grafts & 128 & 129 & 2 & 6 \\
\hline
\end{tabular}

*One sequential graft was not resolvable by consensus; S.C. read it as occluded, and M.B. read it as diseased.

tOne independent graft was not resolvable by consensus; S.C. read it as open, and M.B. read it as occluded.

an intervening stress test, percutaneous transluminal coronary angioplasty, presence of coronary symptoms, beta blockers, angiotensin-converting enzyme inhibitors, aspirin, statins, calcium blockers, coumadin, age, and weight were examined for possible contribution to occlusion. This was accomplished with both univariate and multivariate logistic regression. None of these variables, taken singly, were significant for predicting occlusion. Using the 3 most likely variables from the univariate analyses, namely, diabetes $(P$ $=.3)$, need for a stress test $(P=.3)$, and angiotensinconverting enzyme inhibitors $(P=.4)$, in a multivariate logistic regression resulted in no significant predictive value for any of the variables.

\section{Discussion}

Although endoscopically harvested veins for CABG generally ensure favorable patient-related outcomes, ${ }^{1-6}$ they have not been subject to the long-term follow-up of traditionally harvested saphenous veins. There is a concern that greater damage might be done to a vein with endoscopic harvesting than there is with traditional open harvesting. ${ }^{2,5,7,8}$ There have been several studies that have examined this question. Meyer and colleagues, ${ }^{8}$ in a small study, showed no histologic differences in intima, media, or adventitia of endoscopically versus traditionally harvested veins. Furthermore, von Willebrand factor protein and CD34 were not different between the 2 methods. Griffith and colleagues ${ }^{7}$ showed similar endothelial, elastic lamina, and smooth muscle continuity as well as medial and adventitial connective tissue uniformity between traditional versus endoscopically harvested veins. Using a small subset of veins taken from a large group of patients, Crouch and colleagues ${ }^{5}$ reported no decrement in vein integrity regardless of harvest technique. Kiaii and colleagues ${ }^{2}$ also reported minimal and nonsignificant changes in vein histology independent of harvest technique. These data indicate that endoscopically harvested veins should perform as well as traditionally harvested veins.

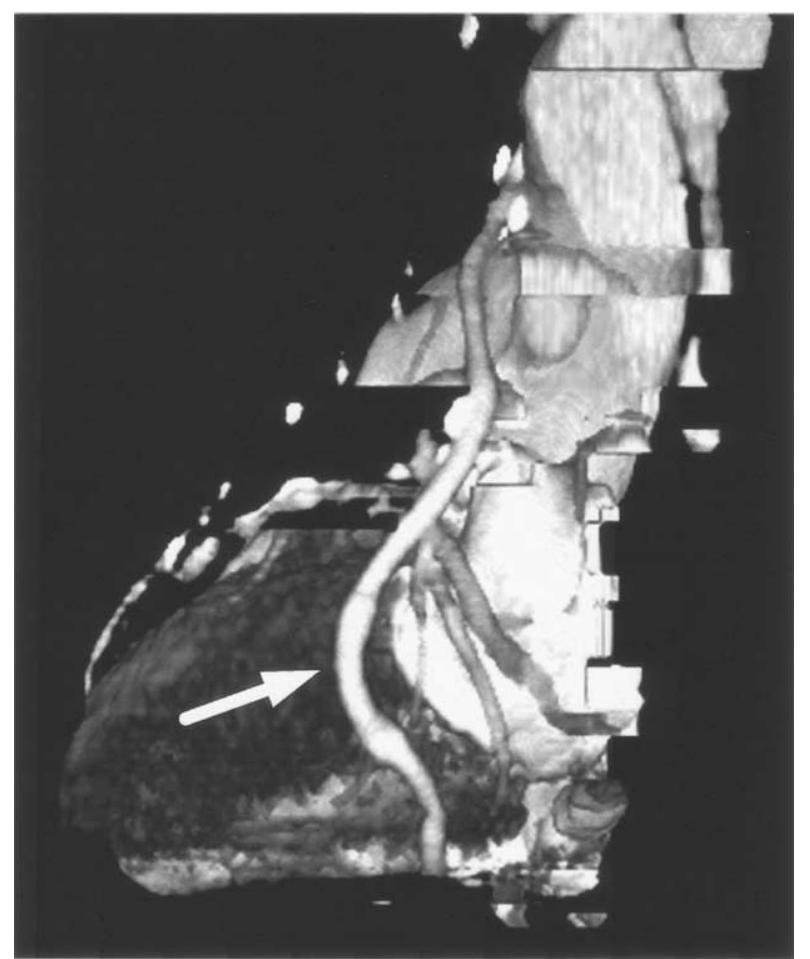

Figure 1. Contrast-enhanced EBCT of a 71-year-old patient 3 years after CABG, with patent graft to obtuse marginal (arrow), followed by $\mathbf{3 0} \%$ stenosis in graft before insertion into the posterior descending artery.

The technique of noninvasive angiography for bypass grafts was first described in $1983 .^{12}$ EBCT seems well suited for imaging of the coronary artery. It has a unique combination of high temporal $(100 \mathrm{~ms} / \mathrm{slice})$ and spatial $(0.35 \times 0.35 \times 2.5 \mathrm{~mm})$ resolutions, allowing visualization of small lesions. Furthermore, ECG triggering allows image acquisition during the slow portion of coronary motion (diastole). ${ }^{13,14}$ Contrast-enhanced EBCT (or contrast-enhanced electron beam angiography [EBA]) is an emerging technology with the potential for obtaining essentially noninvasive coronary arteriograms (Figures 1 and 2). The use of EBA to detect the patency of CABG was reported as early as $1986 .{ }^{15}$ Baumgartner and colleagues ${ }^{16}$ used EBCT in symptomatic patients in the early postoperative period and found 5 of $51(9.8 \%)$ independent SVGs occluded. Dai and colleagues ${ }^{17}$ used EBCT to evaluate coronary grafts at 15 months (range 7 days-120 months) after CABG. Of 296 SVGs placed in 150 patients, $228(77 \%)$ were patent. Of note in their study is the comparison of 7 patients with 12 grafts in whom EBCT showed 7 patent and 5 occluded grafts, findings that were confirmed by conventional angiography. Lu and colleagues ${ }^{18}$ compared EBCT with conventional angiography in 26 patients with 91 grafts. They found a sensitivity of $87.5 \%$ (14/16 stenosed grafts correctly identified) and a $90.7 \%$ specificity (68/75 patent grafts). 
SVGs, which are generally of large caliber and have little cardiac motion, are especially well suited for noninvasive imaging with EBA. Flow studies (sequential image acquisition to determine the rate of contrast enhancement at a particular point in the anatomy) demonstrate graft patency with sensitivities of $93 \%$ to $96 \%$ and specificities of $86 \%$ to $100 \%{ }^{19-21}$ Using 3-dimensional visualization in patients post-CABG demonstrated a sensitivity of $92 \%$ to $100 \%$ and a specificity of $91 \%$ to $100 \%$ for establishing the patency of SVGs compared with conventional coronary angiography. ${ }^{18,22,23}$ A recent study by Achenbach and colleagues ${ }^{22}$ demonstrated a sensitivity of $97 \%$ and specificity of $100 \%$ for obstructions of SVG using EBA, compared with invasive cardiac catheterization.

From these studies it is apparent that with greater than 90\% accuracy, contrast EBCT can be used for noninvasive tracking of patients who underwent CABG with saphenous vein or arterial grafts.

The long-term patency rates of venous grafts used for CABG are a known factor when using traditionally harvested saphenous veins. These rates must be used comparatively to ensure that endoscopic harvest carries no added risk. Early trials showed 69\% patency at 1 year, ${ }^{24} 77 \%$ patency between 9 and 18 months, ${ }^{25}$ and $82 \%$ patency at 18 months and 5 years. ${ }^{26}$ Despite significant technical advances since these early studies, graft failure remains high at $15 \%$ to $30 \%$ at 1 year and progressing to $50 \%$ by 10 years. ${ }^{27,28}$ Manninen and colleagues ${ }^{28}$ found $87 \%$ of SVGs open at 2 years (range 13-31 months). This value included 4 diseased but patent grafts. Fitzgibbon and colleagues ${ }^{29}$ reported patency rates of $81 \%$ and $75 \%$ at 1 and 5 years, respectively, in a large series of patients.

More recently, Souza and colleagues ${ }^{30}$ using a vein harvest technique that includes taking a surrounding pedicle of tissue with the saphenous vein, reported an occlusion rate of $4.8 \%$ (6/124 grafts, $95.2 \%$ patency) at 18 months (range 9-24 months). This article provides a benchmark of early graft patency. Calculations using the data of their article show that the Clopper-Pearson 95\% confidence intervals are $2.1 \%$ for the lower limit and $9.4 \%$ for the upper limit.

Our data are almost identical to Souza and colleagues' data ${ }^{30}$ for both prospective and retrospective groups. Even if there is a small underestimation of occlusion rates because of the EBCT testing, our data clearly demonstrate that EVH does not contribute to a higher incidence of graft failure. Indeed, our patency rates compare quite favorably with those commonly accepted and are likely better than those reported by Dai and colleagues, ${ }^{17}$ who reported patency rates of $77 \%$ for coronary grafts using EBCT over a very wide range of times.

Of interest are the nearly identical findings for the 3.7year grafts versus the recent grafts. This indicates that early graft failure likely accounts for nearly all of the total occlu-

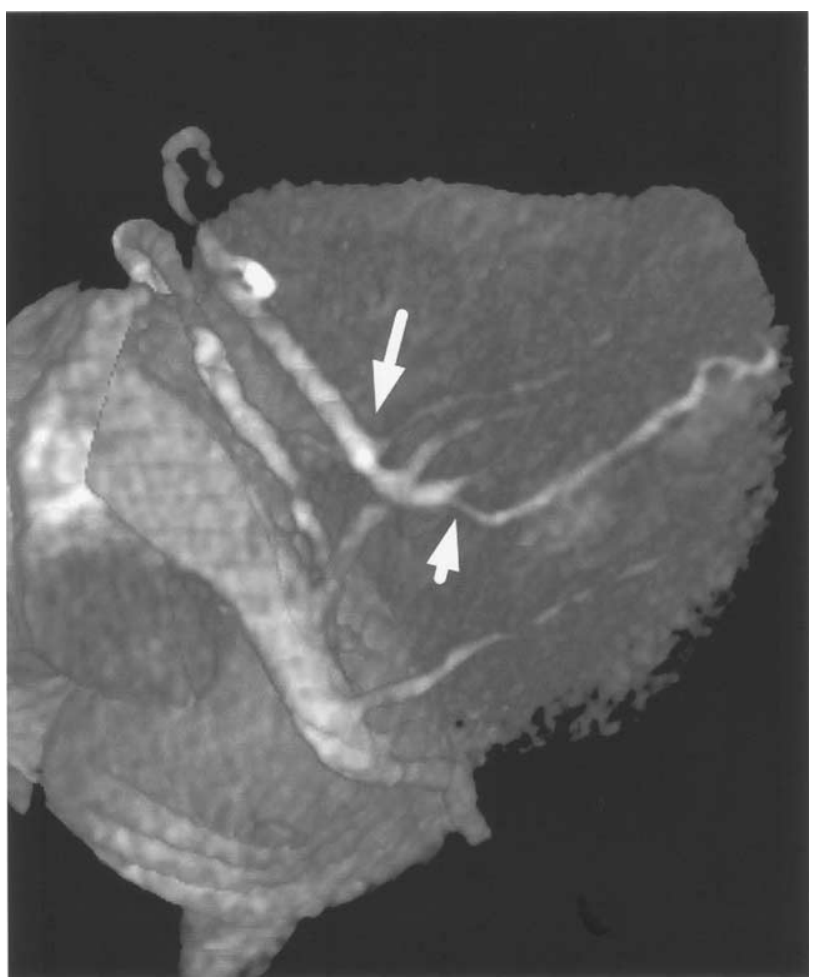

Figure 2. EBCT of a patient with widely patent sequential graft to the posterior descending artery (arrow) and to the posterolateral marginal branch (arrowhead).

sions that occur. Longer term follow-up seems essential to determine whether there is a progression of occlusions in endoscopically harvested saphenous veins as there is for conventionally harvested veins.

These low rates of vein graft occlusion answer one of the final challenges to the widespread application of EVH. With the excellent patient satisfaction, good short-term outcomes in terms of infections, pain, and costs, and the low occlusion rates we report, EVH should be the standard for saphenous vein harvest.

We thank R. Patel, PhD, for his review of the statistical analyses used in this article.

\section{References}

1. Allen KB, Griffith GL, Heimansohn DA, Robison RJ, Matheny RG, Schier JJ, et al. Endoscopic versus traditional saphenous vein harvesting: a prospective, randomized trial. Ann Thorac Surg. 1998;66:26-32.

2. Kiaii B, Moon BC, Massel D, Langlois Y, Austin TW, Willoughby A, et al. A prospective randomized trial of endoscopic versus conventional harvesting of the saphenous vein in coronary artery bypass surgery. J Thorac Cardiovasc Surg. 2002;123:204-12.

3. Bitondo JM, Daggett WM, Torchiana DF, Akins CW, Hilgenberg AD, Vlahakes GJ. Endoscopic versus open saphenous vein harvest: a comparison of postoperative wound complications. Ann Thorac Surg. 2002;73:523-8.

4. Puskas JD, Wright CE, Miller PK, Anderson TE, Gott JP, Brown WM 3rd, et al. A randomized trial of endoscopic versus open saphenous 
vein harvest in coronary bypass surgery. Ann Thorac Surg. 1999;68: 1509-12.

5. Crouch JD, O'Hair DP, Keuler JP, Barragry TP, Werner PH, Kleinman LH. Open versus endoscopic saphenous vein harvesting: wound complications and vein quality. Ann Thorac Surg. 1999;68:1513-6.

6. Davis Z, Jacobs HK, Zhang M, Thomas C, Castellanos Y. Endoscopic vein harvest for coronary artery bypass grafting: technique and outcomes. J Thorac Cardiovasc Surg. 1998;116:228-35.

7. Griffith GL, Allen KB, Waller BF, Heimanshon DA, Robison RJ, Schier JJ, et al. Endoscopic and traditional vein harvest: a histologic comparison. Ann Thorac Surg. 2000;69:520-3.

8. Meyer DM, Rogers TE, Jessen MD, Estrera AS, Chin AK. Histologic evidence of the safety of endoscopic saphenous vein graft preparation. Ann Thorac Surg. 2000;70:487-91.

9. Black EA, Guzik TJ, West NE, Campbell K, Pillai R, Ratnatunga C, et al. Minimally invasive saphenous vein harvesting: effects on endothelial and smooth muscle function. Ann Thorac Surg. 2001;71:1503-7.

10. Allen KB, Heimansohn DA, Griffith GL, Robison RJ, Schier JJ, Fitzgerald EB, et al. Endoscopic versus traditional saphenous vein harvesting: a prospective, randomized trial with 18-month follow-up. Circulation. 1999;100(Suppl 18):I-93-4 (abstract).

11. Clopper CJ, Pearson ES. The use of confidence or fiducial limits illustrated in the case of the binomial. Biometrika. 1934;26:404-13.

12. McKay CR, Brundage BH, Ullyot DJ, Turley K, Lipton MJ, Ebert PA. Evaluation of early postoperative coronary artery bypass grafts patency by contrast-enhanced computed tomography. J Am Coll Cardiol. 1983;2:312-7.

13. Thomas PJ, McCollough CH, Ritman EL. An electron-beam CT approach for transvenous coronary arteriography. J Comput Assist Tomogr. 1995;19:383-9.

14. Uchino A, Kato A, Kudo S. CT angiography using electron-beam computed tomography (EBCT): a phantom study. Radiat Med. 1997; 15:273-6.

15. Bateman TM, Gray RJ, Whiting JS, Matloff JM, Berman DS, Forrester JS. Cine computed tomographic evaluation of aortocoronary bypass graft patency. J Am Coll Cardiol. 1986;8:693-8.

16. Baumgartner F, Brundage B, Bleweis M, Lee J, Farrario T, Georgiou D. Feasibility of ultrafast computed tomography in the early evaluation of coronary bypass patency. Am J Card Imaging. 1996;10:170-4.

17. Dai R, Zhang S, Lu B, Cao C, He S, Bai H, et al. Three-dimensional reconstruction of electron beam computed tomography angiography for evaluating coronary artery bypass grafts. Chin Med J (Engl). 1998;111:588-92.

18. Lu B, Dai RP, Jing BL, Bai H, He S, Zhuang N, et al. Evaluation of coronary artery bypass graft patency using three-dimensional reconstruction and flow study on electron beam tomography. J Comput Assist Tomogr. 2000;24:663-70.

19. Bateman TM, Gray RJ, Whiting JS, Sethna DH, Berman DS, Matloff JM, et al. Prospective evaluation of ultrafast cardiac computed tomography for determination of coronary bypass graft patency. Circulation. 1987;75:1018-24.

20. Stanford W, Krachmer M, Galvin JR. Ultrafast computed tomography in assessing coronary bypass grafts. Am J Card Imaging. 1991;5:21-8.

21. Dai R, Zhang, S, Lu B, Cao C, He S, Bai H, et al. Electron beam CT angiography with three-dimensional reconstruction in the evaluation of coronary artery bypass grafts. Acad Radiol. 1998;5:863-7.

22. Achenbach S, Moshage W, Ropers D, Nossen J, Bachman K. Noninvasive, three-dimensional visualization of coronary artery bypass grafts by electron beam tomography. Am J Cardiol. 1997;79:856-61.

23. Ha JW, Cho SY, Shim WH, Chung N, Jang Y, Lee HM, et al. Noninvasive evaluation of coronary artery bypass graft patency using three-dimensional angiography obtained with contrast-enhanced electron beam CT. Am J Roentgenol. 1999;172:1055-9.

24. Detre K, Peduzzi P, Murphy M, Hultgren H, Thomsen J, Oberman A, et al, and the Veterans Administration Cooperative Study Group for Coronary Arterial Occlusive Disease. Effect of bypass surgery for coronary arterial occlusive disease: effect of bypass surgery on survival in patients in low- and high-risk subgroups delineated by the use of simple clinical variables. Circulation. 1981;63:1329-38.

25. European Coronary Surgery Study Group. Long-term results of prospective randomized study of coronary artery bypass surgery in stable angina pectoris. Lancet. 1982;2:1173-80.

26. CASS Principal Investigators and Their Associates. Coronary Artery Surgery Study (CASS): a randomized trial of coronary artery bypass surgery. Survival data. Circulation. 1983;68:939-50.

27. Mehta D, Issat MB, Bryan AJ, Angelini GD. Towards the prevention of vein graft failure. Int J Cardiol. 1997;62(Suppl 1):555-63.

28. Manninen HI, Jaakkola P, Suhonen M, Rehnberg S, Vuorenniemi R, Matsi PJ. Angiographic predictors of graft patency and disease progression after coronary artery bypass grafting with arterial and venous grafts. Ann Thorac Surg. 1998;66:1289-94.

29. Fitzgibbon GM, Kafka HP, Leach AJ, Keon WJ, Hooper JD, Burton JR. Coronary bypass graft fate and patient outcome: angiographic follow-up of 5,065 grafts related to survival and reoperation in 1,388 patients during 25 years. J Am Coll Cardiol. 1996;28:616-26.

30. Souza DSR, Bomfim V, Skoglund H, Dashwood MR, Borowiec JW, Bodin L, et al. High early patency of saphenous vein graft for coronary artery bypass harvested with surrounding tissue. Ann Thorac Surg. 2001;71:797-800. 